\title{
A biological pathway linking inflammation and depression: activation of indoleamine 2,3-dioxygenase
}

This article was published in the following Dove Press journal:

Neuropsychiatric Disease and Treatment

I 2 July 201 I

Number of times this article has been viewed

\section{David M Christmas \\ JP Potokar \\ Simon JC Davies}

Academic Unit of Psychiatry, School of Social and Community Medicine, University of Bristol, Bristol, UK

A presentation relating to this manuscript was made by Dr David Christmas at the 9th International Meeting on Clinical Pharmacology in Psychiatry (9th IMCPP) in Copenhagen, Denmark in September 2010
Correspondence: David Christmas Academic Unit of Psychiatry, School of Social and Community Medicine, University of Bristol Oakfield House, Oakfield Grove, Bristol,

Avon BS8 2BN, UK

Tel +44 II 733 I 4012

Fax +44 II7 33। 4026

Email david.christmas@bristol.ac.uk
Abstract: This article highlights the evidence linking depression to increased inflammatory drive and explores putative mechanisms for the association by reviewing both preclinical and clinical literature. The enzyme indoleamine 2,3-dioxygenase is induced by proinflammatory cytokines and may form a link between immune functioning and altered neurotransmission, which results in depression. Increased indoleamine 2,3-dioxygenase activity may cause both tryptophan depletion and increased neurotoxic metabolites of the kynurenine pathway, two alterations which have been hypothesized to cause depression. The tryptophan-kynurenine pathway is comprehensively described with a focus on the evidence linking metabolite alterations to depression. The use of immune-activated groups at high risk of depression have been used to explore these hypotheses; we focus on the studies involving chronic hepatitis $\mathrm{C}$ patients receiving interferon-alpha, an immune activating cytokine. Findings from this work have led to novel strategies for the future development of antidepressants including inhibition of indoleamine 2,3-dioxygenase, moderating the cytokines which activate it, or addressing other targets in the kynurenine pathway.

Keywords: depression, inflammation, indoleamine 2,3-dioxygenase, kynurenine, serotonin, tryptophan

\section{Introduction}

Clinical depression is extremely common and debilitating. It is ranked by the World Health Organization as the fourth largest cause of burden amongst all diseases and the leading nonfatal disease burden. ${ }^{1}$ Current treatments have only moderate efficacy, with around 35\% remission after initial treatment and approximately $70 \%$ remission after four cumulative treatment trials. ${ }^{2}$ Therefore it is necessary to look beyond currently characterized neurotransmitter systems to understand the pathophysiology of depression in order to produce more effective treatments in the long-term.

Emerging evidence demonstrates that: a) major depression is associated with increased inflammatory drive $;^{3-5}$ and b) provoking an acute inflammatory response in healthy humans can result in depression-like behaviors and symptoms. ${ }^{6,7}$ The nature of these associations has yet to be delineated with respect to causality. Determining a plausible biological mechanism remains an important step. In this article we review a putative mechanism by which increased inflammation may affect mood, by altering activity of the enzyme indoleamine 2,3-dioxygenase (IDO).

\section{Depression, mood, and immune functioning}

There is a growing body of literature that suggests that major depression is associated with an increased inflammatory drive. People with depression display increased 
plasma concentrations of pro-inflammatory cytokines such as: interleukin-1 (IL-1) ) $^{3,8}$ (also increased in cerebrospinal fluid $[\mathrm{CSF}]^{9}$ ), interleukin-6 (IL-6),,$^{3,4,9-11}$ tumor necrosis factor (TNF) ${ }^{4,12}$ and other acute phase proteins, such as C-reactive protein (CRP), ${ }^{3}$ haptoglobin ${ }^{11}$ and neopterin. ${ }^{13}$ There have been some negative findings, ${ }^{14,15}$ but the overall picture is sufficient to support both a positive metaanalysis exploring the associations of CRP, IL-1, IL-6 and depression ${ }^{3}$ and the suggestion that plasma IL-6 and soluble IL-2-receptor should be considered biomarkers of depression. ${ }^{16}$

Treatment of depression with antidepressants may reverse derangements in these inflammatory markers. ${ }^{17}$ Fluoxetine treatment for depression reduces serum IL-6 in patients. ${ }^{18}$ Imipramine, clomipramine, venlafaxine, fluoxetine, sertraline and trazodone have been shown to reduce the interferon-gamma (INF- $\gamma$ )/IL-10 ratio of in vitro human blood samples (a ratio of pro-inflammatory/antiinflammatory drive), consistent with an anti-inflammatory effect. ${ }^{19-21}$ In addition, nonresponders to selective serotonin reuptake inhibitor (SSRI) medication continue to exhibit raised IL-6 levels, raising the possibility that response to treatment is linked to a reduction of IL- $6 .^{22}$ Preliminary evidence also exists that an increased body temperature may also be present in depression and reversed by successful treatment. ${ }^{23}$

Abnormalities of plasma cytokines may occur in various psychiatric disorders. In bipolar disorder, increased IL-1, IL-6 and TNF have been reported at differing stages of the illness. ${ }^{24}$ In schizophrenia, less consistent results have been found, but a recent meta-analysis reported increased plasma IL-6 and IL-1 receptor antagonist levels. ${ }^{25}$ However, exploring these illnesses in detail is beyond the scope of this review, which focuses upon the changes seen in major depression.

"Sickness behavior" is a characteristic constellation of symptoms (hypomotility, hyperthermia, hypophagia, hyperalgesia, decreased interest in exploration, decreased sexual activity, increased sleep) observed in animals following immune activation ${ }^{26-28}$ that has been proposed to be a model of depression. ${ }^{29}$ Activating an immune response by injecting lipopolysaccharide (LPS), ${ }^{30} \mathrm{IL}_{-1},{ }^{31}$ or $\mathrm{IFN}^{32}$ results in characteristic sickness behavior. In addition, an acute inflammatory challenge has been reported to produce depression-like responses in two other animal models of depression, the tail suppression and sucrose consumption tests, after the initial illness behaviors have subsided. ${ }^{33}$ The biochemical and behavioral effects of challenges like these may also be augmented by social stress, ${ }^{34}$ analogous to social risk factors for depression. ${ }^{35}$ Pretreatment with the antidepressant imipramine has been found to attenuate LPS-induced sickness behavior. ${ }^{30}$

Provoking an acute inflammatory response in healthy humans, for example via injection of endotoxin, ${ }^{6,7}$ IL-6, ${ }^{36}$ or IFN- $\beta,{ }^{37}$ also produces symptoms similar to those seen in depression (such as fatigue, lack of motivation, anorexia, poor sleep). Although these symptoms are short-lived, subtle cognitive symptoms similar to those seen in depression are also present. These include feelings of social isolation ${ }^{6,38}$ and psychomotor slowing. ${ }^{37}$ The symptoms produced by challenge tests such as these resolve quickly and are not prolonged as is seen in depression.

\section{Immune effects on indoleamine 2,3-dioxygenase}

Indoleamine 2,3-dioxygenase (IDO) and its hepatic equivalent tryptophan 2,3-dioxygenase (TDO) oxygenate tryptophan to form kynurenine ${ }^{39}$ (Figure 1, tryptophan metabolic pathway). The majority of dietary tryptophan is metabolized through this pathway with less than $1 \%$ eventually being available for conversion (via hydroxylation by tryptophan hydroxylase, TPH, and decarboxylation) into $5 \mathrm{HT}$ in the brain. ${ }^{40}$ Under normal circumstances, TDO is the dominant enzyme, but IDO is subject to induction during immune activation. At such times the effect of increasing the combined availability of IDO and TDO means that the overall capacity of the kynurenine pathway is much increased. Therefore serum tryptophan concentration can be reduced by $25 \%-50 \%$, leaving proportionally less tryptophan available for conversion to serotonin. ${ }^{41-43}$

IDO is ubiquitous throughout the organs and present in human immune cells including macrophages and microglia. ${ }^{44}$ Interferons are important in the induction of IDO. The sites of action are two IFN-stimulated response elements (ISREs) and IFN- $\gamma$ activated site (GAS) element sequences found in the $5^{\prime}$ promoter region of the IDO gene. ${ }^{45,46}$ IDO can be stimulated by INF- $\gamma$ in macrophages and microglia. ${ }^{47,48}$ However, other cytokines such as TNF in combination with IL-6 or IL-1 can induce IDO via signal transducer and activator of transcription protein (STAT)-independent pathways involving p38 mitogen-activated protein kinase (p38 MAPK) and nuclear factor-kappa B (NF- $\mathrm{BB}){ }^{49}$

A proxy measure for in vivo IDO activity, like many enzymes, is the ratio of product:substrate (in this case kynurenine:tryptophan). Thus, an increase in the ratio reflects 


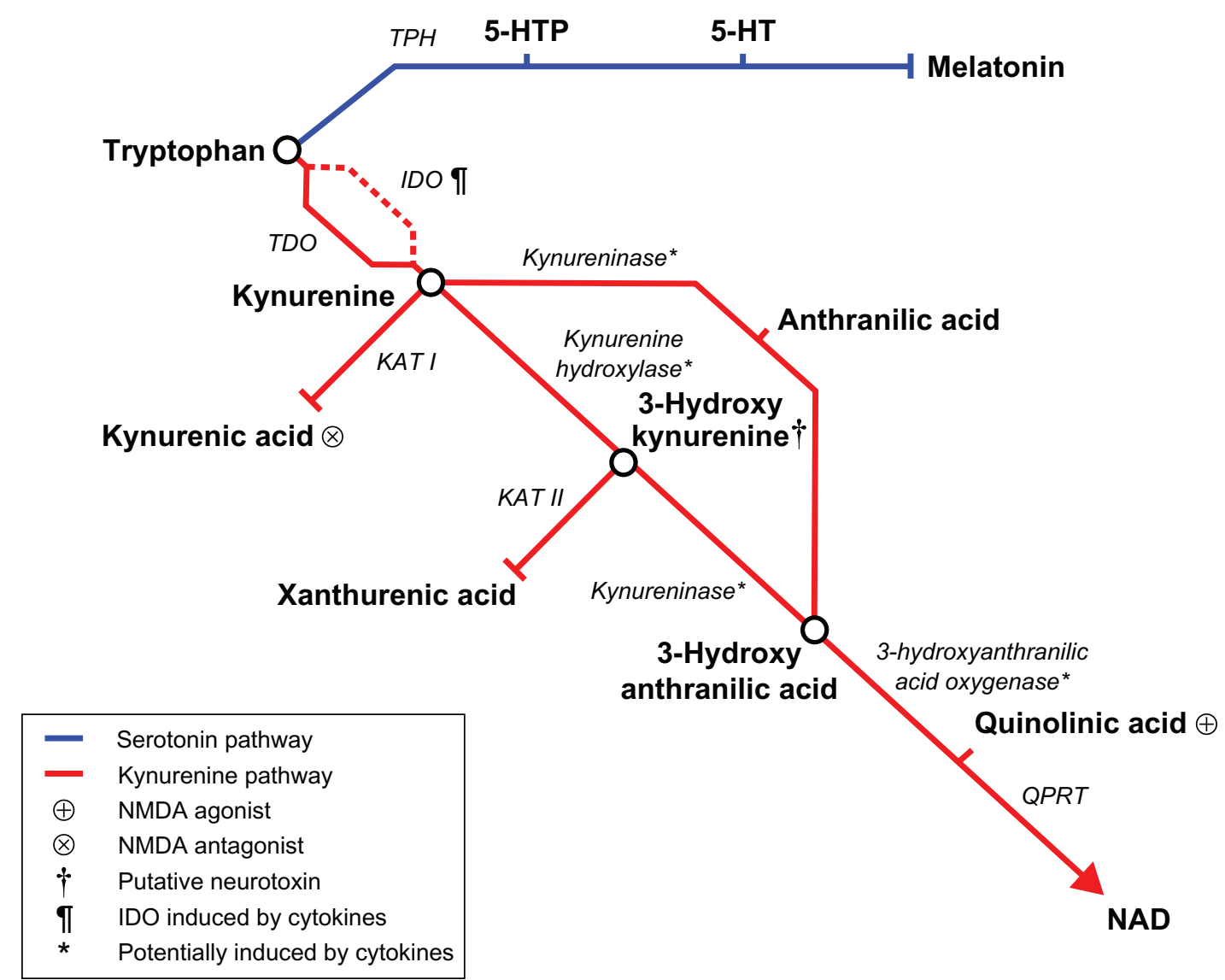

Figure I Tryptophan metabolic pathway.

Abbreviations: 5-HT, serotonin; 5-HTP, 5-hydroxytryptophan; TPH, tryptophan hydroxylase; TDO, tryptophan dioxygenase; IDO, indoleamine 2,3-dioxygenase; KAT I, kynurenine aminotransferase I; KAT II, kynurenine aminotransferase II; QPRT, quinolinic acid phosphoribosyltransferase; NAD, nicotinamide adenine dinucleotide; NMDA, $\mathrm{N}$-methyl-D-asparate.

greater enzyme activity, a decrease indicates lower activity and no change implies the same activity. ${ }^{50}$

\section{Animal models of IDO activation and mood}

Animal models support the hypothesis that immune-related sickness behavior may be related to increased activity of IDO. IDO activity, measured by either the plasma concentration of kynurenine pathway metabolites or IDO mRNA expression, is increased in animal sickness behavior. ${ }^{51}$ This activation is partly mediated by IFN- $\gamma$ and TNF, since IFN- $\gamma$ knockout mice, and animals with prior treatment with the TNF antagonist etanercept, both show reduced IDO activation and depressive behaviors (in the forced swim and tail suspension tests). ${ }^{52}$ IDO knock-out mice lack the expected depressive behaviors secondary to an immune challenge, despite normal cytokine responses. ${ }^{51}$ In addition, inhibition of IDO blocks the depressive behavior in these models ${ }^{51,53}$ and administration of kynurenine induces depressive behavior in a dose-dependent manner. ${ }^{53}$

\section{A human model of IDO activation and depression: hepatitis $C$ cohorts treated with IFN- $\alpha$}

As described above, acute inflammatory challenges reproduce sickness behavior and depressive cognitions in healthy humans. Clearly, it is ethically difficult to continue challenges like these for prolonged periods due to the high degree of morbidity they cause. Therefore, an alternative is to study patient cohorts who require long-term pro-inflammatory treatments for an underlying condition.

An ideal high-risk population that can be used to assess the effects of increased inflammatory drive is chronic hepatitis $\mathrm{C}(\mathrm{HCV})$ patients being treated with IFN- $\alpha$ therapy. HCV is a common illness, affecting approximately 170 million people worldwide. ${ }^{54,55}$ Without treatment, it causes considerable morbidity and mortality; it leads to chronic infection in approximately $85 \%$ of cases, cirrhosis in $15 \%-20 \%$, and in cirrhosis patients, $1 \%-4 \%$ progress to hepatocellular carcinoma. ${ }^{56} \mathrm{HCV}$ patients undergo an IFN- $\alpha$-based treatment regime for between 6 and 12 months. 
During this time there are high rates of depression, estimated at approximately 25\% 57,58 and 33\% $\%^{59,60}$ (although some studies report higher prevalences, a precise figure is difficult to determine due to methodological differences between studies; those reporting higher rates report self-rated symptoms rather than utilizing standardized objective depression scales ${ }^{61}$ ).

In $\mathrm{HCV}$, IFN- $\alpha$ increases inflammatory drive with elevations in pro-inflammatory cytokines (eg, IL-1, IL-6, IL-8 and $\mathrm{TNF}^{62,63}$ ) similar to that observed in depression. ${ }^{3}$ Although IFN- $\alpha$ is peripherally administered, increases in IFN- $\alpha$, IL-6 and monocyte chemoattractant protein-1 have been observed in the CSF of this group, providing evidence of central immunomodulatory effects. In conjunction with the increase in pro-inflammatory cytokines, the kynurenine:tryptophan ratio is increased (reflecting increased IDO activity) in both the blood and CSF. ${ }^{64,65}$

There are two current hypotheses regarding the mechanism of how increased inflammatory drive and IDO activation may cause depression in the HCV group - tryptophan depletion and kynurenine toxicity.

\section{Tryptophan depletion}

Increased IDO activity should reduce the availability of its substrate, the dietary essential amino acid tryptophan. ${ }^{66}$ Serotonin (5HT) is produced from tryptophan via 5-hydroxytryptophan (5HTP). Under normal conditions the rate-limiting enzyme tryptophan hydroxylase is only about $50 \%$ saturated. Therefore 5 HT synthesis varies with tryptophan availability. ${ }^{67}$ The evidence linking 5HT dysfunction to depressive illness has been well described. Many effective antidepressants (such as SSRIs) work primarily on increasing serotonin availability in the synaptic cleft. ${ }^{68}$ This antidepressant effect can be temporarily reversed using the acute tryptophan depletion (ATD) technique, which acutely lowers 5HT by lowering the brain availability of its precursor tryptophan. ${ }^{69,70}$ Lower concentrations of plasma tryptophan have also been reported in depression. ${ }^{71}$ Imaging studies have also reported central changes in the 5HT system in depression including reduced 5HT transporters, ${ }^{72,73}$ reduced 5HT-1a receptors, ${ }^{74,75}$ and reduced 5HT-2a receptors. ${ }^{76}$

In the HCV cohort, reductions in plasma tryptophan (and 5HT, although this is an inexact measure, as much plasma 5HT is stored by platelets and released when they are stimulated, such as in venepuncture, resulting in inconsistent results $^{77}$ ) have been observed. ${ }^{78}$ SSRIs are highly effective at treating or preventing IFN- $\alpha$ associated depression. ${ }^{79,80}$ However, tryptophan does not have clear access to the brain from the plasma: $95 \%$ is protein-bound in the plasma, leaving 5\% free to access the CNS. ${ }^{81}$ It is transported across the blood-brain barrier via active transport in competition with the other large neutral amino acids (LNAAs): valine, leucine, isoleucine, methionine, phenylalanine and tyrosine. ${ }^{82}$ Plasma tryptophan concentrations correlate poorly with those of the CSF. ${ }^{83}$ Thus, a more accurate measure of brain tryptophan availability is the tryptophan:LNAA ratio. ${ }^{84}$ This ratio remains unchanged in IFN- $\alpha$ therapy for hepatitis $\mathrm{C}$ and does not appear to vary with depressive symptoms. ${ }^{64}$ In keeping with this, CSF levels of tryptophan do not change during interferon treatment. ${ }^{65}$ However, this does not entirely disprove the $5 \mathrm{HT}$ reduction theory, as the $5 \mathrm{HT}$ metabolite 5-hydroxyindoleacetic acid (5HIAA) is reduced and this reduction correlates with depressive symptoms. ${ }^{85}$ Therefore although absolute tryptophan levels appear not to be altered, an overall reduction in brain 5HT turnover may still be related to depression.

Different measures of brain 5HT functioning are required to further delineate these changes. A sensitive method is polysomnography. 5HT is important in the regulation of sleep $^{86}$ and sleep disturbances prior to interferon treatment have been suggested to predict later depression. ${ }^{87}$ Serotonergic compounds (such as SSRIs) increase time until onset of rapid eye movement (REM) sleep (increased REM latency). Decreasing serotonin availability, by ATD, has the opposite effect, decreased REM latency. ${ }^{88-90}$ Alterations in REM latency have been utilized by our group to detect differences in physiological potency between different SSRIs, ${ }^{91}$ proving this technique's sensitivity to alterations in central 5HT functioning. Using a within-subjects design we observed no significant alteration in REM latency after 6 weeks IFN- $\alpha$ treatment (Pers comm, David N Christmas, 2011). Our finding of no decrease in REM latency is similar to an independent study by a different group that observed an REM latency increase during IFN- $\alpha$ treatment. ${ }^{92}$ The difference between these studies has yet to be explained, but importantly neither observed the decrease in REM latency predicted by the 5 HT depletion hypothesis.

An alternative explanation for the lack of decrease in REM latency is that IDO activation may also affect REM sleep via a different mechanism to 5HT depletion. Preclinical evidence suggests that glutamatergic neurons are important in the genesis of REM sleep: indeed kynurenic acid (which is produced from kynurenine and is an $N$-methyl$D$-aspartate [NMDA] antagonist) can abolish experimentally induced REM sleep. ${ }^{93}$ The control of REM sleep is complex, with 5HT, acetylcholine, glutamate and gamma-amino hydroxybutyric acid (GABA) all playing important roles. ${ }^{94}$ 
At risk of oversimplification, REM-on neurons appear to be glutamatergic (under tonic inhibition by GABA neurons) and REM-off neurons serotonergic or noradrenergic. Therefore, altering the balance between kynurenic acid and quinolinic acid (also on the kynurenine metabolic pathway and an NMDA agonist [Figure 1]) may also alter both REM latency and duration. However, IFN- $\alpha$ does not alter the CSF kynurenic acid:quinolinic acid ratio. ${ }^{65}$ Therefore the preliminary conclusion is that neither central $5 \mathrm{HT}$ functioning nor NMDA activation is altered during IFN- $\alpha$ treatment. However, further research is required to form a conclusive picture.

\section{Kynurenine excess}

The products of IDO activation have also been hypothesized to cause depression. Under normal circumstances the liver enzyme TDO ${ }^{95}$ metabolizes tryptophan into kynurenine. TDO is not induced by immune activation, but is constitutively active and is induced by tryptophan, tyrosine, histidine, glucocorticoids and kynurenine. TDO primarily serves nicotinamide adenine dinucleotide synthesis (Figure 1) and is the rate-limiting enzyme of the pathway. Under circumstances of immune activation, IDO activity is increased, causing detectable increases in kynurenine and decreases in tryptophan. ${ }^{41,43,96}$ Kynurenine is mostly hydroxylated (kynurenine hydroxylase) into 3-hydroxykynurenine (3-HK). Kynureninase acts upon both 3-HK and kynurenine; on 3-HK to form 3-hydroxyanthranilic acid (3-HAA); and on kynurenine to form anthranilic acid (although the latter conversion accounts for only a minority of kynureninase activity). 3-HAA is converted into quinolinic acid by 3 -hydroxyanthranilic acid oxygenase. Kynurenine can also be converted into kynurenic acid by kynurenine aminotransferase I and 3-HK into xanthurenic acid by kynurenine aminotransferase II.

Some of these kynurenine metabolites modulate neurotransmission and some may be directly neurotoxic. As mentioned above, quinolinic acid is an NMDA agonist and kynurenic acid an NMDA antagonist. 3-HK is believed to be neurotoxic due to increased formation of reactive oxygen species involved in neuronal apoptosis. ${ }^{97,98}$ Quinolinic acid may also be neurotoxic due to increased oxidative stress, ${ }^{99,100}$ whereas kynurenic acid has been postulated to be neuroprotective. ${ }^{101}$ Under conditions of immune activation, preclinical evidence suggests kynurenine aminotransferase activity is unchanged whereas, in addition to IDO, kynurenine 3-hydroxylase, kynureninase and 3-hydroxyanthranilic acid oxygenase activity may be increased ${ }^{51,102}$ (although the evidence for induction of the last enzyme is contradictory, possibly due to species differences). Therefore, kynurenine metabolism is shifted toward the $3-\mathrm{HK}$ /quinolinic acid pathway and away from the kynurenic acid pathway, which should result in greater neurotoxic and reduced neuroprotective metabolites. The relative balance of neurotoxic and neuroprotective pathways of kynurenine metabolism can be assessed indirectly in vivo by the kynurenine:kynurenic acid ratio. ${ }^{64,103}$

During IFN- $\alpha$ treatment, the plasma kynurenine:kynurenic acid ratio is increased and this correlates with depressive symptoms. ${ }^{64}$ CSF kynurenine and quinolinic acid also increase and these increases correlate with increases in depressive symptoms. However, the kynurenine:kynurenic acid ratio does not alter as CSF kynurenic acid also rises. ${ }^{65}$

One cross-sectional study observed increased IDO activity and a decreased kynurenic acid:kynurenine ratio (reflecting a shift towards neurotoxicity) in otherwise healthy major depression sufferers compared to controls. ${ }^{104}$ However, as yet no studies have been undertaken to identify whether these differences resolve once the depressive episode has been successfully treated.

\section{Future drug targets}

Some preliminary studies have already reported possible efficacy of anti-inflammatory drugs in depression. A doubleblind, randomized clinical trial reported an advantage of reboxetine and the cyclo-oxygenase- 2 inhibitor celecoxib over reboxetine and placebo. ${ }^{105}$ In addition, an open pilot study reported a benefit of augmentation with aspirin in depressed patients with no early response to an SSRI. ${ }^{106}$ However, both these cases require larger more robust trials to prove their efficacy. A further problem may occur with this route; there is a large increased risk of gastrointestinal bleeding when SSRIs and nonsteroidal anti-inflammatory drugs are combined ${ }^{107}$ and cyclo-oxygenase- 2 inhibitors alone have been associated with increased cardiovascular and allcause mortality above other anti-inflammatory drugs. ${ }^{108,109}$ Therefore alternative strategies may be required to maintain a favorable risk-benefit ratio.

Utilizing the above evidence, it is possible to identify future novel pharmacological targets for antidepressants. The first target could be antagonizing or reducing IDO activity. The drug 1-methlytryptophan can inhibit IDO and has been successful in reducing depressive behaviors following inflammatory challenges in animal models. ${ }^{51}$ Clinical trials using 1-methyltryptophan have commenced in humans as a putative anticancer agent (trial identifier NCT00567931, http://clinicaltrials.gov). However, there is some debate as 
to whether it inhibits human IDO in vivo. ${ }^{110}$ In addition, IDO may have immunosuppressive actions in itself, highlighting the complexity of immune functioning. ${ }^{110}$

A different avenue may be to block the pro-inflammatory cytokines that are raised in depression and known to induce IDO. Monoclonal antibodies are available for human use, to treat rheumatoid arthritis or inflammatory bowel disease, to block both TNF (such as infliximab or etanercept) and IL-6 (tocilizumab). Indeed, a clinical trial at Emory University evaluating the efficacy of infliximab in treatment resistant depression is approaching completion (trial identifier NCT00463580, http://clinicaltrials.gov).

A third approach may be to block the downstream actions of excess kynurenine metabolites. As the ratio of NMDA receptor agonism:antagonism appears to be shifted towards agonism in depression, NMDA antagonists may have antidepressant effects. Unfortunately human subjects exposed to direct NMDA antagonists have experienced serious side effects such as sedation, memory impairment and psychosis. ${ }^{11,112}$ Thus design of NMDA manipulating compounds may require novel strategies, such as targeting NMDA cotransmitters. Despite this, several small studies have shown promising results for the use of ketamine, an NMDA receptor antagonist, for treatment-resistant depression. ${ }^{113-117}$

\section{Summary}

In summary, major depression appears to be accompanied by increases in some pro-inflammatory cytokines. In keeping with this, inducing increased inflammation in animals or humans results in characteristic sickness behavior, or full-blown major depression in the high-risk HCV cohort. In tandem with markers of increased inflammation, IDO is activated, both peripherally and centrally. Although the evidence falls short of proving a causative link between inflammation, IDO and mood, the diversity and congruence of evidence suggests this pathway is a promising field for future drug targets.

\section{Disclosure}

The authors report no conflicts of interest in this work.

\section{References}

1. Ustun TB, Ayuso-Mateos JL, Chatterji S, Mathers C, Murray CJ. Global burden of depressive disorders in the year 2000. Br J Psychiatry. 2004;184:386-392.

2. Rush AJ, Trivedi MH, Wisniewski SR, et al. Acute and longer-term outcomes in depressed outpatients requiring one or several treatment steps: a STAR*D report. Am J Psychiatry. 2006;163(11):1905-1917.
3. Howren MB, Lamkin DM, Suls J. Associations of depression with C-reactive protein, IL-1, and IL-6: a meta-analysis. Psychosom Med. 2009;71(12):171-186.

4. Kim YK, Na KS, Shin KH, Jung HY, Choi SH, Kim JB. Cytokine imbalance in the pathophysiology of major depressive disorder. Prog Neuropsychopharmacol Biol Psychiatry. 2007;31(5):1044-1053.

5. Maes M, Bosmans E, Meltzer HY. Immunoendocrine aspects of major depression. Relationships between plasma interleukin-6 and soluble interleukin-2 receptor, prolactin and cortisol. Eur Arch Psychiatry Clin Neurosci. 1995;245(3):172-178.

6. Eisenberger NI, Inagaki TK, Mashal NM, Irwin MR. Inflammation and social experience: an inflammatory challenge induces feelings of social disconnection in addition to depressed mood. Brain Behav Immun. 2010;24(4):558-563.

7. Reichenberg A, Yirmiya R, Schuld A, et al. Cytokine-associated emotional and cognitive disturbances in humans. Arch Gen Psychiatry. 2001;585(5):445-452.

8. Owen BM, Eccleston D, Ferrier IN, Young AH. Raised levels of plasma interleukin-1beta in major and postviral depression. Acta Psychiatr Scand. 2001;103(3):226-228.

9. Levine J, Barak Y, Chengappa KN, Rapoport A, Rebey M, Barak V. Cerebrospinal cytokine levels in patients with acute depression. Neuropsychobiology. 1999;40(4):171-176.

10. Maes M, Meltzer HY, Bosmans E, et al. Increased plasma concentrations of interleukin-6, soluble interleukin-6, soluble interleukin-2 and transferrin receptor in major depression. J Affect Disord. 1995;34(4):301-309.

11. Zorrilla EP, Luborsky L, McKay JR, et al. The relationship of depression and stressors to immunological assays: a meta-analytic review. Brain Behav Immun. 2001;15(3):199-226.

12. Hestad KA, Tonseth S, Stoen CD, Ueland T, Aukrust P. Raised plasma levels of tumor necrosis factor alpha in patients with depression: normalization during electroconvulsive therapy. J ECT. 2003;19(4):183-188.

13. Maes M, Scharpe S, Meltzer HY, et al. Increased neopterin and interferon-gamma secretion and lower availability of L-tryptophan in major depression: further evidence for an immune response. Psychiatry Res. 1994;54(2):143-160.

14. Brambilla F, Maggioni M. Blood levels of cytokines in elderly patients with major depressive disorder. Acta Psychiatr Scand. 1998;97(4):309-313.

15. Carpenter LL, Heninger GR, Malison RT, Tyrka AR, Price LH. Cerebrospinal fluid interleukin (IL)-6 in unipolar major depression. J Affect Disord. 2004;79(1-3):285-289.

16. Mossner R, Mikova O, Koutsilieri E, et al. Consensus paper of the WFSBP Task Force on Biological Markers: biological markers in depression. World J Biol Psychiatry. 2007;8(3):141-174.

17. Maes M, Yirmyia R, Noraberg J, et al. The inflammatory and neurodegenerative (I\&ND) hypothesis of depression: leads for future research and new drug developments in depression. Metab Brain Dis. 2009;24(1):27-53.

18. Sluzewska A, Rybakowski JK, Laciak M, Mackiewicz A, Sobieska M, Wiktorowicz K. Interleukin-6 serum levels in depressed patients before and after treatment with fluoxetine. Ann NY Acad Sci. 1995;762:474-476.

19. Lin A, Song C, Kenis G, et al. The in vitro immunosuppressive effects of moclobemide in healthy volunteers. J Affect Disord. 2000;58(1):69-74.

20. Maes M, Song C, Lin AH, et al. Negative immunoregulatory effects of antidepressants: inhibition of interferon-gamma and stimulation of interleukin-10 secretion. Neuropsychopharmacology. 1999;20(4):370-379.

21. Kubera M, Lin AH, Kenis G, Bosmans E, van BD, Maes M. Anti-Inflammatory effects of antidepressants through suppression of the interferon-gamma/interleukin-10 production ratio. $J$ Clin Psychopharmacol. 2001;21(2):199-206.

22. O'Brien SM, Scully P, Fitzgerald P, Scott LV, Dinan TG. Plasma cytokine profiles in depressed patients who fail to respond to selective serotonin reuptake inhibitor therapy. J Psychiatr Res. 2007;41(3-4):326-331. 
23. Szuba MP, Guze BH, Baxter LR Jr. Electroconvulsive therapy increases circadian amplitude and lowers core body temperature in depressed subjects. Biol Psychiatry. 1997;42(12):1130-1137.

24. Berk M, Kapczinski F, Andreazza AC, et al. Pathways underlying neuroprogression in bipolar disorder: focus on inflammation, oxidative stress and neurotrophic factors. Neurosci Biobehav Rev. 2011;35(3):804-817.

25. Potvin S, Stip E, Sepehry AA, Gendron A, Bah R, Kouassi E. Inflammatory cytokine alterations in schizophrenia: a systematic quantitative review. Biol Psychiatry. 2008;63(8):801-808.

26. Hart BL. Biological basis of the behavior of sick animals. Neurosci Biobehav Rev. 1988;12(2):123-137.

27. Dantzer R. Cytokine-induced sickness behavior: mechanisms and implications. Ann N Y Acad Sci. 2001;933:222-234.

28. Kent S, Bluthe RM, Kelley KW, Dantzer R. Sickness behavior as a new target for drug development. Trends Pharmacol Sci. 1992;13(1):24-28.

29. Smith RS. The macrophage theory of depression. Med Hypotheses. 1991;35(4):298-306.

30. Yirmiya R. Endotoxin produces a depressive-like episode in rats. Brain Res. 1996;711(1-2):163-174.

31. Kent S, Rodriguez F, Kelley KW, Dantzer R. Reduction in food and water intake induced by microinjection of interleukin-1 beta in the ventromedial hypothalamus of the rat. Physiol Behav. 1994;56(5): 1031-1036.

32. Fahey B, Hickey B, Kelleher D, O’Dwyer AM, O'Mara SM. The widely-used anti-viral drug interferon-alpha induces depressive- and anxiogenic-like effects in healthy rats. Behav Brain Res. 2007;182(1): 80-87.

33. Frenois F, Moreau M, O’Connor J, et al. Lipopolysaccharide induces delayed FosB/DeltaFosB immunostaining within the mouse extended amygdala, hippocampus and hypothalamus, that parallel the expression of depressive-like behavior. Psychoneuroendocrinology. 2007;32(5):516-531.

34. Anisman H, Poulter MO, Gandhi R, Merali Z, Hayley S. Interferonalpha effects are exaggerated when administered on a psychosocial stressor backdrop: cytokine, corticosterone and brain monoamine variations. J Neuroimmunol. 2007;186(1-2):45-53.

35. Righetti-Veltema M, Conne-Perreard E, Bousquet A, Manzano J. Risk factors and predictive signs of postpartum depression. J Affect Disord. 1998;49(3):167-180.

36. Spath-Schwalbe E, Hansen K, Schmidt F, et al. Acute effects of recombinant human interleukin-6 on endocrine and central nervous sleep functions in healthy men. J Clin Endocrinol Metab. 1998;83(5):1573-1579.

37. Brydon L, Harrison NA, Walker C, Steptoe A, Critchley HD. Peripheral inflammation is associated with altered substantia nigra activity and psychomotor slowing in humans. Biol Psychiatry. 2008;63(11):1022-1029.

38. Eisenberger NI, Inagaki TK, Rameson LT, Mashal NM, Irwin MR. An fMRI study of cytokine-induced depressed mood and social pain: the role of sex differences. Neuroimage. 2009;47(3):881-890.

39. Schwarcz R, Pellicciari R. Manipulation of brain kynurenines: glial targets, neuronal effects, and clinical opportunities. J Pharmacol Exp Ther. 2002;303(1):1-10.

40. Bender DA. Biochemistry of tryptophan in health and disease. Mol Aspects Med. 1983;6(2):101-197.

41. Werner ER, Fuchs D, Hausen A, et al. Tryptophan degradation in patients infected by human immunodeficiency virus. Biol Chem Hoppe Seyler. 1988;369(5):337-340.

42. Fuchs D, Forsman A, Hagberg L, et al. Immune activation and decreased tryptophan in patients with HIV-1 infection. $J$ Interferon Res. 1990;10(6):599-603.

43. Fuchs D, Moller AA, Reibnegger G, Stockle E, Werner ER, Wachter H. Decreased serum tryptophan in patients with HIV-1 infection correlates with increased serum neopterin and with neurologic/psychiatric symptoms. J Acquir Immune Defic Syndr. 1990;39(9):873-876.
44. Dale WE, Dang Y, Brown OR. Tryptophan metabolism through the kynurenine pathway in rat brain and liver slices. Free Radic Biol Med. 2000;29(2):191-198.

45. Konan KV, Taylor MW. Importance of the two interferonstimulated response element (ISRE) sequences in the regulation of the human indoleamine 2,3-dioxygenase gene. J Biol Chem. 1996;271(32):19140-19145.

46. Chon SY, Hassanain HH, Pine R, Gupta SL. Involvement of two regulatory elements in interferon-gamma-regulated expression of human indoleamine 2,3-dioxygenase gene. J Interferon Cytokine Res. 1995;15(6):517-526.

47. Heyes MP, Saito K, Markey SP. Human macrophages convert L-tryptophan into the neurotoxin quinolinic acid. Biochem $J$. 1992;283(Pt 3):633-635.

48. Aberati-Giani D, Cesura AM. Expression of the kynurenine enzymes in macrophages and microglial cells: regulation by immune modulators. Amino Acids. 1998;14(1-3):251-255.

49. Fujigaki H, Saito K, Fujigaki S, et al. The signal transducer and activator of transcription 1alpha and interferon regulatory factor 1 are not essential for the induction of indoleamine 2,3-dioxygenase by lipopolysaccharide: involvement of p38 mitogen-activated protein kinase and nuclear factor-kappaB pathways, and synergistic effect of several proinflammatory cytokines. J Biochem. 2006;139(4):655-662.

50. Schrocksnadel K, Wirleitner B, Winkler C, Fuchs D. Monitoring tryptophan metabolism in chronic immune activation. Clin Chim Acta. 2006;364(1-2):82-90.

51. O'Connor JC, Lawson MA, Andre C, et al. Induction of IDO by bacille Calmette-Guerin is responsible for development of murine depressivelike behavior. J Immunol. 2009;182(5):3202-3212.

52. O'Connor JC, Andre C, Wang Y, et al. Interferon-gamma and tumor necrosis factor-alpha mediate the upregulation of indoleamine 2,3dioxygenase and the induction of depressive-like behavior in mice in response to bacillus Calmette-Guerin. J Neurosci. 2009;29(13): 4200-4209.

53. O'Connor JC, Lawson MA, Andre C, et al. Lipopolysaccharide-induced depressive-like behavior is mediated by indoleamine 2,3-dioxygenase activation in mice. Mol Psychiatry. 2009;14(5):511-522.

54. Alter MJ. Epidemiology of hepatitis C. Hepatology. 1997;26(3 Suppl 1): 62S-65S.

55. Shepard CW, Finelli L, Alter MJ. Global epidemiology of hepatitis C virus infection. Lancet Infect Dis. 2005;5(9):558-567.

56. Lauer GM, Walker BD. Hepatitis C virus infection. $N$ Engl J Med. 2001;345(1):41-52.

57. Dieperink E, Ho SB, Thuras P, Willenbring ML. A prospective study of neuropsychiatric symptoms associated with interferon-alpha- $2 \mathrm{~b}$ and ribavirin therapy for patients with chronic hepatitis C. Psychosomatics. 2003;44(2):104-112.

58. Horikawa N, Yamazaki T, Izumi N, Uchihara M. Incidence and clinical course of major depression in patients with chronic hepatitis type $\mathrm{C}$ undergoing interferon-alpha therapy: a prospective study. Gen Hosp Psychiatry. 2003;25(1):34-38.

59. Hauser P, Khosla J, Aurora H, et al. A prospective study of the incidence and open-label treatment of interferon-induced major depressive disorder in patients with hepatitis C. Mol Psychiatry. 2002;7(9): 942-947.

60. Kraus MR, Schafer A, Faller H, Csef H, Scheurlen M. Psychiatric symptoms in patients with chronic hepatitis $\mathrm{C}$ receiving interferon alfa-2b therapy. J Clin Psychiatry. 2003;64(6):708-714.

61. Schafer A, Wittchen HU, Seufert J, Kraus MR. Methodological approaches in the assessment of interferon-alfa-induced depression in patients with chronic hepatitis $\mathrm{C}$ - a critical review. Int J Methods Psychiatr Res. 2007;16(4):186-201.

62. Bonaccorso S, Puzella A, Marino V, et al. Immunotherapy with interferon-alpha in patients affected by chronic hepatitis $\mathrm{C}$ induces an intercorrelated stimulation of the cytokine network and an increase in depressive and anxiety symptoms. Psychiatry Res. 2001;105(1-2): $45-55$. 
63. Wichers MC, Kenis G, Koek GH, Robaeys G, Nicolson NA, Maes M. Interferon-alpha-induced depressive symptoms are related to changes in the cytokine network but not to cortisol. J Psychosom Res. 2007;62(2):207-214.

64. Wichers MC, Koek GH, Robaeys G, Verkerk R, Scharpe S, Maes M. IDO and interferon-alpha-induced depressive symptoms: a shift in hypothesis from tryptophan depletion to neurotoxicity. Mol Psychiatry. 2005;10(6):538-544.

65. Raison CL, Dantzer R, Kelley KW, et al. CSF concentrations of brain tryptophan and kynurenines during immune stimulation with IFN-alpha: relationship to CNS immune responses and depression. Mol Psychiatry. 2010;15(4):393-403.

66. Rose WC, Haines WJ, Warner DT. The amino acid requirement of man. V. The role of lysine, arginine and tryptophan. Journal of Biological Chemistry. 1950;206(1):421-430.

67. Schaechter JD, Wurtman RJ. Serotonin release varies with brain tryptophan levels. Brain Res. 1990;532(1-2):203-210.

68. Anderson IM, Ferrier IN, Baldwin RC, et al. Evidence-based guidelines for treating depressive disorders with antidepressants: a revision of the 2000 British Association for Psychopharmacology guidelines. J Psychopharmacol. 2008;22(4):343-396.

69. Delgado PL, Charney DS, Price LH, Aghajanian GK, Landis H, Heninger GR. Serotonin function and the mechanism of antidepressant action. Reversal of antidepressant-induced remission by rapid depletion of plasma tryptophan. Arch Gen Psychiatry. 1990; 47(5):411-418.

70. Hood SD, Bell CJ, Nutt DJ. Acute tryptophan depletion. Part I: rationale and methodology. Aust N Z J Psychiatry. 2005;39(7):558-564.

71. Maes M, Meltzer HY, Scharpe S, et al. Relationships between lower plasma L-tryptophan levels and immune-inflammatory variables in depression. Psychiatry Res. 1993;49(2):151-165.

72. Reimold M, Batra A, Knobel A, et al. Anxiety is associated with reduced central serotonin transporter availability in unmedicated patients with unipolar major depression: a [11C]DASB PET study. Mol Psychiatry. 2008;13(6):606-613, 557.

73. Joensuu M, Tolmunen T, Saarinen PI, et al. Reduced midbrain serotonin transporter availability in drug-naive patients with depression measured by SERT-specific [(123)I] nor-beta-CIT SPECT imaging. Psychiatry Res. 2007;154(2):125-131.

74. Sargent PA, Kjaer KH, Bench CJ, et al. Brain serotonin1 A receptor binding measured by positron emission tomography with [11C] WAY-100635: effects of depression and antidepressant treatment. Arch Gen Psychiatry. 2000;57(2):174-180.

75. Drevets WC, Thase ME, Moses-Kolko EL, et al. Serotonin-1 A receptor imaging in recurrent depression: replication and literature review. Nucl Med Biol. 2007;34(7):865-877.

76. Yatham LN, Liddle PF, Shiah IS, et al. Brain serotonin2 receptors in major depression: a positron emission tomography study. Arch Gen Psychiatry. 2000;57(9):850-858.

77. Doggrell SA. The role of 5-HT on the cardiovascular and renal systems and the clinical potential of 5-HT modulation. Expert Opin Investig Drugs. 2003;12(5):805-823.

78. Bonaccorso S, Marino V, Puzella A, et al. Increased depressive ratings in patients with hepatitis $\mathrm{C}$ receiving interferon-alpha-based immunotherapy are related to interferon-alpha-induced changes in the serotonergic system. J Clin Psychopharmacol. 2002;22(1): 86-90.

79. Kraus MR, Schafer A, Faller H, Csef H, Scheurlen M. Paroxetine for the treatment of interferon-alpha-induced depression in chronic hepatitis C. Aliment Pharmacol Ther. 2002;16(6):1091-1099.

80. Musselman DL, Lawson DH, Gumnick JF, et al. Paroxetine for the prevention of depression induced by high-dose interferon alfa. $N$ Engl J Med. 2001;344(13):961-966.

81. McMenamy RH. Binding of indole analogues to human serum albumin. Effects of fatty acids. J Biol Chem. 1965;240(11):4235-4243.

82. Oldendorf WH, Szabo J. Amino acid assignment to one of three bloodbrain barrier amino acid carriers. Am J Physiol. 1976;230(1):94-98.
83. Salomon RM, Kennedy JS, Johnson BW, et al. Association of a critical CSF tryptophan threshold level with depressive relapse. Neuropsychopharmacology. 2003;28(5):956-960.

84. Fernstrom JD. Diet-induced changes in plasma amino acid pattern: effects on the brain uptake of large neutral amino acids, and on brain serotonin synthesis. J Neural Transm Suppl. 1979;(15): $55-67$.

85. Raison CL, Borisov AS, Majer M, et al. Activation of central nervous system inflammatory pathways by interferon-alpha: relationship to monoamines and depression. Biol Psychiatry. 2009;65(4):296-303.

86. Jouvet M. Sleep and serotonin: an unfinished story. Neuropsychopharmacology. 1999;21(2 Suppl):24S-27S.

87. Capuron L, Miller AH. Cytokines and psychopathology: lessons from interferon-alpha. Biol Psychiatry. 2004;56(11):819-824.

88. Bhatti T, Gillin JC, Seifritz E, et al. Effects of a tryptophan-free amino acid drink challenge on normal human sleep electroencephalogram and mood. Biol Psychiatry. 1998;43(1):52-59.

89. Moore P, Gillin C, Bhatti T, et al. Rapid tryptophan depletion, sleep electroencephalogram, and mood in men with remitted depression on serotonin reuptake inhibitors. Arch Gen Psychiatry. 1998;55(6):534-539.

90. Carhart-Harris RL, Nutt DJ, Munafo MR, Christmas DM, Wilson SJ. Equivalent effects of acute tryptophan depletion on REM sleep in ecstasy users and controls. Psychopharmacology (Berl). 2009;206(2):187-196.

91. Wilson SJ, Bailey JE, Rich AS, Adrover M, Potokar J, Nutt DJ. Using sleep to evaluate comparative serotonergic effects of paroxetine and citalopram. Eur Neuropsychopharmacol. 2004;14(15):367-372.

92. Raison CL, Rye DB, Woolwine BJ, et al. Chronic interferon-alpha administration disrupts sleep continuity and depth in patients with hepatitis c: association with fatigue, motor slowing, and increased evening cortisol. Biol Psychiatry. 2010;68(10):942-949.

93. Boissard R, Gervasoni D, Schmidt MH, Barbagli B, Fort P, Luppi PH. The rat ponto-medullary network responsible for paradoxical sleep onset and maintenance: a combined microinjection and functional neuroanatomical study. Eur J Neurosci. 2002;16(10):1959-1973.

94. Fuller PM, Saper CB, Lu J. The pontine REM switch: past and present. J Physiol. 2007;584(Pt 3):735-741.

95. Knox WE, Mehler AH. The conversion of tryptophan to kynurenine in liver. I. The coupled tryptophan peroxidase-oxidase system forming formylkynurenine. J Biol Chem. 1950;187(1):419-430.

96. Silva NM, Rodrigues CV, Santoro MM, Reis LF, Alvarez-Leite JI, Gazzinelli RT. Expression of indoleamine 2,3-dioxygenase, tryptophan degradation, and kynurenine formation during in vivo infection with Toxoplasma gondii: induction by endogenous gamma interferon and requirement of interferon regulatory factor 1. Infect Immun. 2002;70(2):859-868.

97. Okuda S, Nishiyama N, Saito H, Katsuki H. 3-Hydroxykynurenine, an endogenous oxidative stress generator, causes neuronal cell death with apoptotic features and region selectivity. $J$ Neurochem. 1998;70(1):299-307.

98. Stone TW. Endogenous neurotoxins from tryptophan. Toxicon. 2001;39(1):61-73.

99. Santamaria A, Galvan-Arzate S, Lisy V, et al. Quinolinic acid induces oxidative stress in rat brain synaptosomes. Neuroreport. 2001;12(4):871-874.

100. Behan WM, McDonald M, Darlington LG, Stone TW. Oxidative stress as a mechanism for quinolinic acid-induced hippocampal damage: protection by melatonin and deprenyl. Br J Pharmacol. 1999;128(8):1754-1760.

101. Stone TW, Addae JI. The pharmacological manipulation of glutamate receptors and neuroprotection. Eur J Pharmacol. 2002;447(2-3):285-296.

102. Saito K, Crowley JS, Markey SP, Heyes MP. A mechanism for increased quinolinic acid formation following acute systemic immune stimulation. J Biol Chem. 1993;268(21):15496-15503. 
103. Wu HQ, Guidetti P, Goodman JH, et al. Kynurenergic manipulations influence excitatory synaptic function and excitotoxic vulnerability in the rat hippocampus in vivo. Neuroscience. 2000;97(2):243-251.

104. Myint AM, Kim YK, Verkerk R, Scharpe S, Steinbusch H, Leonard B. Kynurenine pathway in major depression: evidence of impaired neuroprotection. J Affect Disord. 2007;98(1-2):143-151.

105. Muller N, Schwarz MJ, Dehning S, et al. The cyclooxygenase-2 inhibitor celecoxib has therapeutic effects in major depression: results of a double-blind, randomized, placebo controlled, add-on pilot study to reboxetine. Mol Psychiatry. 2006;11(7):680-684.

106. Mendlewicz J, Kriwin P, Oswald P, Souery D, Alboni S, Brunello N. Shortened onset of action of antidepressants in major depression using acetylsalicylic acid augmentation: a pilot open-label study. Int Clin Psychopharmacol. 2006;21(4):227-231.

107. Loke YK, Trivedi AN, Singh S. Meta-analysis: gastrointestinal bleeding due to interaction between selective serotonin uptake inhibitors and non-steroidal anti-inflammatory drugs. Aliment Pharmacol Ther. 2008;27(1):31-40.

108. Kerr SJ, Sayer GP, Whicker SD, Rowett DS, Saltman DC, Mant A. All-cause mortality of elderly Australian veterans using COX-2 selective or non-selective NSAIDs: a longitudinal study. Br J Clin Pharmacol. 2011;71(6):936-942.

109. Abraham NS, El-Serag HB, Hartman C, Richardson P, Deswal A. Cyclooxygenase-2 selectivity of non-steroidal anti-inflammatory drugs and the risk of myocardial infarction and cerebrovascular accident. Aliment Pharmacol Ther. 2007;25(8):913-924.
110. Lob S, Konigsrainer A, Rammensee HG, Opelz G, Terness P. Inhibitors of indoleamine-2,3-dioxygenase for cancer therapy: can we see the wood for the trees? Nat Rev Cancer. 2009;9(6):445-452.

111. Bergink V, van Megen HJ, Westenberg HG. Glutamate and anxiety. Eur Neuropsychopharmacol. 2004;14(3):175-183.

112. Swanson CJ, Bures M, Johnson MP, Linden AM, Monn JA, Schoepp DD. Metabotropic glutamate receptors as novel targets for anxiety and stress disorders. Nat Rev Drug Discov. 2005;4(2):131-144.

113. Aan het Rot M, Collins KA, Murrough JW, et al. Safety and efficacy of repeated-dose intravenous ketamine for treatment-resistant depression. Biol Psychiatry. 2010;67(2):139-145.

114. Berman RM, Cappiello A, Anand A, et al. Antidepressant effects of ketamine in depressed patients. Biol Psychiatry. 2000;47(4):351-354.

115. Mathew SJ, Murrough JW, aan het Rot M, Collins KA, Reich DL, Charney DS. Riluzole for relapse prevention following intravenous ketamine in treatment-resistant depression: a pilot randomized, placeb-controlled continuation trial. Int J Neuropsychopharmacol. 2010;13(1):71-82.

116. Machado-Vieira R, Yuan P, Brutsche N, et al. Brain-derived neurotrophic factor and initial antidepressant response to an N-methylD-aspartate antagonist. J Clin Psychiatry. 2009;70(12):1662-1666.

117. Zarate CA Jr, Singh JB, Carlson PJ, et al. A randomized trial of an N-methyl-D-aspartate antagonist in treatment-resistant major depression. Arch Gen Psychiatry. 2006;63(8):856-864.
Neuropsychiatric Disease and Treatment

\section{Publish your work in this journal}

Neuropsychiatric Disease and Treatment is an international, peerreviewed journal of clinical therapeutics and pharmacology focusing on concise rapid reporting of clinical or pre-clinical studies on a range of neuropsychiatric and neurological disorders. This journal is indexed on PubMed Central, the 'PsycINFO' database and CAS, and is the official

\section{Dovepress}

journal of The International Neuropsychiatric Association (INA). The manuscript management system is completely online and includes a very quick and fair peer-review system, which is all easy to use. Visit http://www.dovepress.com/testimonials.php to read real quotes from published authors. 